\title{
Risk Factors Associated With the Incidence of Hoof Disorders in Crossbred Dairy Cattle under Field Conditions
}

\author{
Rohit Kumar ${ }^{1}$, Mukund A. Kataktalware ${ }^{2 *}$, S. Senani ${ }^{3}$, M. Sivaram ${ }^{2}$, \\ G. Letha Devi ${ }^{3}$, S. Jeyakumar ${ }^{2}$ and K.P. Ramesha ${ }^{2}$ \\ ${ }^{1}$ ICAR-National Dairy Research Institute, Karnal-132001, India \\ ${ }^{2}$ Southern Regional Station, ICAR-National Dairy Research Institute, \\ Bengaluru- 560 030, India \\ ${ }^{3}$ ICAR-National Institute of Animal Nutrition and Physiology, Bengaluru- 560 030, India \\ *Corresponding author
}

Keywords

Hoof disorders,

Crossbred dairy cattle, Risk factors

Article Info

Accepted:

20 February 2019

Available Online:

10 March 2019

\section{A B S T R A C T}

The major objectives of the present study were to estimate the incidence of hoof disorders and to identify the various risk factors associated with the hoof disorders in crossbred dairy cattle maintained under field conditions in the state of Karnataka, India. A total of 204 crossbred dairy cattle were investigated for hoof disorders. The overall incidence of hoof disorders was found to be $30.4 \%$. The Holstein Friesian crossbred dairy cows (36.2\%) were more vulnerable to hoof disorders than Jersey crossbred dairy cows $(20.8 \%)$. The age of the animals greater than six years $(60 \%)$, parity greater than three $(44 \%)$, body weight greater than $410 \mathrm{~kg}(43 \%)$, animals having white-colored hooves $(58.8 \%)$, injured hocks $(51.7 \%)$ and animal having abnormal claw set $(32.6 \%)$ were significant risk groups for higher incidence of hoof disorders Non-infectious lesions were more common than infectious lesions (94.7 vs 5.3\%). Interdigital hyperplasia was the most commonly observed lesion $(48.48 \%)$ followed by scissor claws $(25 \%)$, horizontal cracks $(18.95 \%)$, heel horn erosion $(4.54 \%)$, white line disease $(2.27 \%)$ and foot rot $(0.76 \%)$. Thus, our study establishes that non-infectious lesions like interdigital hyperplasia, scissor claws, horizontal cracks and white line diseases were the major hoof disorders in the study area compared to infectious lesions (heel horn erosion and foot rot). It can also be concluded that HF crossbred were more vulnerable to hoof disorder than Jersey crossbred and there was an increase in the incidence of hoof disorders with the advancement of age, higher body weight, light coloured hooves, injured hock conditions and abnormal claw set in crossbred dairy cattle.

\section{Introduction}

Lameness is a serious concern of dairy cattle worldwide and hoof health examination is an essential step in lameness monitoring. Previous studies reported that hoof disorders are majorly responsible for the occurrence of lameness in dairy cattle (Somers and O’Grady, 2015; Solano et al., 2016). Recently, Sadiq et al., (2017), have found that $87.5 \%$ of lame animals were suffered from claw lesions and Moreira et al., (2018), found 
that hoof lesions were present in all the cows having lameness. Various researches have shown that Holstein and crossbred dairy cattle are more vulnerable to lameness (Lohith et al., 2016; Bran et al., 2018) and this can be attributed to their selection for their high milk yielding potential trait which itself make them prone to various production and reproduction related diseases and lameness is one out of them. Aetiology of hoof disorder occurrence is not fully understood but there are various risk factors which influence there development and their predominance varies region to region and according to different environmental conditions. Hoof disorders have also been found in the subclinical state in non lame cattle (Tadich et al., 2010) and they are reported to reduce the milk yield prior to the onset of occurrence of lameness in dairy cattle (Green et al., 2014). Farmers usually present only severe cases of lameness for treatment when hoof disorders are in worse condition and they often underestimate its occurrence (Horseman et al., 2014) and impact on dairy cattle. Once the condition becomes serious it becomes a welfare issue due to pain and discomfort caused to an animal (Whay and Shearer, 2017) and also leads to heavy economic losses to the dairy farmers (Green et al., 2014; Thomas et al., 2016). This makes it important to investigate the dairy herds for hoof disorders and to identify various risk factors associated with them under field conditions. Keeping this in mind the present study was designed to determine the incidence of hoof disorder in the study area and to identify various risk factors associated with hoof disorders.

\section{Materials and Methods}

The present study was carried out in Doddaballapura Taluk of Bengaluru Rural District, Karnataka, India during November 2017 - May 2018. Majority of farmers in the study area were rearing Holstein Friesian
(HF) crossbred and Jersey crossbred dairy cattle. Number of animals maintained per household was two to five mature cows along with their progenies. Therefore, all the mature animals were investigated in each household for once during the study period to determine the incidence of hoof disorders and risk factors associated with incidence of hoof disorders using a questionnaire administered through face to face interactions with farmers by visiting their households door to door and as well as by recording of animal level and herd level factors associated with hoof disorders using standard observation methods. A total of 204 crossbred dairy cattle comprising $127 \mathrm{HF}$ crossbred and 77 Jersey crossbred dairy cattle were investigated during the study period regardless of their lactation status.

\section{Methods used for animal observations}

Data collected using questionnaire included the information regarding the breed, age, parity, various reproductive parameters, intramammary infection, feeding and watering practices, housing conditions, type of flooring and various questions regarding general awareness of the farmers about the hoof health. Hoof examination was done for identifying various hoof disorders based on international claw health atlas (Egger-Danner et al., 2015). Claw set of the animal was assessed by using scorecard given by the American Angus Association (2015), foot score guidelines. Hooves were cleaned and debris was removed from hooves for efficient detection of hoof lesions after proper restraining. Hoof colouration was also recorded during the examination. Right hind foot was taken as reference in all animals for hoof coloration recording as taken by Sogstad et al., (2011), because cleaning the hoof for recording hoof coloration need to wash the hoof thoroughly and remove dirt and debris properly and repeating the same process in all 
the hooves is time consuming under field conditions \& may increase discomfort in animals which can compromise animal cooperation during examination. Body weight of the animals was calculated by a formula given by Johnson et al., (1940), for crossbred dairy cattle which involve measurements of length and body girth in animals. This formula calculate animal body weight in pounds which was later converted into Killograms (Kg). Hock injury was assessed using a 4 point ordinal scale with $0-3$ scoring where 0 and 1 scores were considered clinically normal hocks and 2 and 3 scores were considered clinically injured hocks (Gibbons et al., 2012).

\section{Statistical analysis}

Data obtained was entered in MS Excel 2007 and then loaded into IBM, SPSS statistics version 20.0 in window 10. Basic descriptive analysis was done and the Chi-Square test was performed to find out the association among various risk factors associated with the hoof disorders. A $p$ value less than 0.05 was considered significant.

\section{Results and Discussion}

The overall incidence of hoof disorders was found $30.4 \%$ in the study area and it was found that HF crossbred dairy cattle had a significantly $(\mathrm{p}<0.05)$ higher incidence $(36.2 \%)$ of hoof disorders in comparison to jersey crossbred dairy cattle $(20.8 \%)$ (Table 1). Lohith et al., (2016) have reported an incidence of $28.3 \%$ in Kolar districts of Bengaluru, India and also found a higher incidence of hoof disorders in hf graded (35.2\%) and HF crossbred dairy cattle (10\%) in comparison to Jersey crossbred dairy cattle (6.2\%). Chakrabarti and Kumar (2016) conducted a study in Bihar, India and reported that there was a higher incidence of hoof disorders in crossbred animals $(24.7 \%)$ in comparison to non-descript animals (13.05) and the overall incidence of hoof disorders was $17.52 \%$ in their study. Variation in the overall incidence of hoof disorder in different studies could be due to different managemental practices followed by the farmers in the different regions. Similarly, Bhatt et al., (2016) and Bagate et al., (2012) have found that the occurrence of hoof disorders in HF crossbred cows was higher in comparison to other breeds like Gir and Kankrej. This indicates that the occurrence of hoof disorders is more in HF crossbred dairy cattle in comparison to Jersey crossbred dairy cattle and other indigenous breeds. This can be attributed to the selection of HF crossbred dairy cattle for their high milk yielding potential which itself predisposes them to various diseases condition.

There were two types of infectious lesions and four types of non-infectious lesions found in the study area. Infectious lesions found were heel horn erosion (4.54\%) and foot rot $(0.76 \%)$ and non-infectious lesions found were interdigital hyperplasia $(48.48 \%)$, scissor claw $(25.80 \%)$, horizontal hoof crack $(18.94 \%)$ and white line disease $(2.27 \%)$ (Figure 1). There were higher occurrences of non-infectious lesions (94.7\%) in the study area in comparison to infectious lesions $(5.3 \%)$. Our findings are in agreement with Correa-Valencia et al., (2018) who also found non-infectious lesions (94.4\%) occurrence higher in comparison to infectious lesions $(5.6 \%)$ in Colombia. However, they found eleven different types of foot lesions where we have only found six different types of foot lesions. This difference could be due to large no. of animals (1120) covered by them in a larger area. Different types of lesions found by Moreira et al, (2018) in Brazil and in contrary to our study they found heel horn erosion as the major lesion $(90 \%)$ followed by white line disease (50\%) and digital dermatitis $(33 \%)$. In contrary to our results 
(Figure 1), heel horn erosion was the most prevalent lesion in their study which was present in all the farms followed by digital dermatitis which was present in $96 \%$ of the farms and the sole ulcer was observed in a single animal only. Variation in the results in different studies can be due to different environmental conditions in different areas which predispose an animal to different kind of hoof disorders.

There was a significant effect of age on the incidence of hoof disorders $(p<0.01)$ in the present study. The animal having age $>6$ years found to have a higher incidence of hoof disorders than those who had an age in between 4- 6 years and $<4$ years respectively (Table 1). Dembele et al., (2006) have reported that with advancement in age the incidence of lameness increased and followed an inverted "U" shaped relationship with age. They have observed a higher risk of lameness in an animal having age 7-8 years. Huang et al., (1995) found that the risk for six different foot disease traits increased with age and Rowland et al., (1985) found that susceptibility to lameness increased four folds for cows over 10 years old. This indicates that advancement in the age of an animal is an important factor which is associated with hoof disorder.

An animal having parity greater than 3 had significantly $(\mathrm{p}<0.01)$ higher incidence of hoof disorders than those who had parity $\leq 3$ (table 1). A study by Bagate et al., (2012) has reported that incidence of hoof lesions was more in cows and buffalo above $2^{\text {nd }}$ and $3^{\text {rd }}$ lactation respectively. Bicalho et al., (2009), have reported the prevalence of sole ulcers $4.2 \%$ and $27.8 \%$ for parity 1 and parity $>1$, respectively and for white line disease was $1.0 \%$ and $6.5 \%$ for parity 1 and $>1$, respectively. They found in their study that the digital cushion of primiparous animals was thinner than that of multiparous cows.
Similarly, Raber et al., (2004) have also reported that heifers had thinner digital cushions compared with cows, with a reduction again observed in older cows. This can be the reason behind our findings that parity $\geq 3$ had more incidence of hoof disorders $(44.0 \%)$ than those who had parity $<3(20.8 \%)$. As parity increases animal undergo through more transitional phases in their life which has an impact on hoof health and also on the keratinization process. This indicates that parity has a significant effect on hoof disorders.

The animal having a body weight greater than $410 \mathrm{~kg}$ had a significantly higher incidence of hoof disorders than those who had body weight $\leq 410 \mathrm{~kg}$ (Table 1). Body weight reflects changes in the size and shape of animals over time (Monsi, 1992) and may affect locomotion negatively. The cows selected for larger body size were more often culled due to leg and foot problems than the cows that were selected for small body size (Hansen et al., 1999). As the body weight of the cow increases, it affects the locomotion of the cow. Lohith (2011) have also observed in his study that as the weight of the animal increases the incidences of the hoof disorder also increases. Cows with higher body weight $(>351 \mathrm{~kg}$ ) had an incidence of $54.2 \%$ while cows with lower body weight $(<351 \mathrm{~kg})$ have an incidence ranging from 16 to $30.8 \%$. This shows that the weight increases the increasing trend of hoof disorders. Therefore, based on our findings and results of previous researches it can be suggested that body weight is an important factor associated with the incidence of hoof disorders.

Results of our study showed that animals having higher scores for claw set had significantly $(\mathrm{p}<0.05)$ higher incidence of hoof disorders compared to the animals having symmetrical claw set (Table 1). It was reported by American Angus Association that 
proper foot structure is essential to animal longevity and the problem with claw set can affect structural soundness of hoof. According to the American Angus Association, the symmetrical claw set is ideal claw set which represents a structurally sound foot. Open, divergent claw set and claws having a tendency to curl (Scissors or screw claws) represent unsound claws. Results of our study are in agreement with the foot scoring guidelines of the American Angus Association and based on this it can be concluded that animals having higher scores for claw set have more chances of getting hoof disorders due to their poor structural soundness when compared to the symmetrical claw set which is considered as a structurally sound foot.

An animal having injured hock had significantly $(\mathrm{p}<0.01)$ higher incidence of hoof disorders than those who had normal hock (Table 1). This can be attributed to the prevailing tie stall housing condition and hard flooring (stone slab and concrete) used in the barns in the study area. Mostafa and Maharan (2016) have reported higher hock injury in a tie stall barn with concrete floor (11.9\%). Higher hock injury in the tie-stall barn can be attributed to confinement of the animal at one place due to which their movements are confined which have an effect on hock injury and may be the reason behind more stress on hock in tie-stall barns. In previous studies, it was reported that hock lesions are associated with an increased risk of lameness (Whay et al., 2003; Kielland et al., 2009; Brenninkmeyer et al., 2012). There is no such study which shows the relationship between hoof disorders and hock injury. The reason behind our results can be the tie-stall housing conditions and hard flooring conditions (stone slabs and cemented floors) in animal houses which have an impact on both hoof disorders as well as on hock injury.

Table.1 The overall distribution of categorical (\%) animal level variables for crossbred cows with hoof disorders

\begin{tabular}{|c|c|c|c|c|}
\hline \multicolumn{2}{|l|}{ Variables } & \multirow{2}{*}{$\begin{array}{c}\text { Percentage of affected } \\
\text { animals with hoof disorders } \\
36.2\end{array}$} & \multirow{3}{*}{$\begin{array}{c}\text { Chi-square } \\
\text { value } \\
5.403^{\mathrm{a}}\end{array}$} & \multirow{2}{*}{$\begin{array}{c}\text { P-value } \\
0.014\end{array}$} \\
\hline \multirow{2}{*}{$\begin{array}{l}\text { Genetic } \\
\text { group }\end{array}$} & HF crossbred & & & \\
\hline & Jersey crossbred & 20.8 & & \\
\hline \multirow[t]{3}{*}{ Age } & $<4$ & 21.7 & \multirow[t]{3}{*}{$12.705^{\mathrm{a}}$} & \multirow[t]{3}{*}{0.002} \\
\hline & $4-6$ & 28.6 & & \\
\hline & $>6$ & 60 & & \\
\hline \multirow[t]{2}{*}{ Parity } & $\leq 3$ & 20.8 & \multirow[t]{2}{*}{$12.587^{\mathrm{a}}$} & \multirow[t]{2}{*}{0.001} \\
\hline & $>3$ & 44 & & \\
\hline \multirow{2}{*}{$\begin{array}{l}\text { Body } \\
\text { weight }\end{array}$} & $\leq 410$ & 22.4 & \multirow[t]{2}{*}{$9.746^{\mathrm{a}}$} & \multirow[t]{2}{*}{0.002} \\
\hline & $>410$ & 43 & & \\
\hline \multirow[t]{2}{*}{ Claw set } & Abnormal & 10 & \multirow[t]{2}{*}{$4.359^{\mathrm{a}}$} & \multirow[t]{2}{*}{0.027} \\
\hline & Symmetrical & 32.6 & & \\
\hline \multirow{3}{*}{$\begin{array}{l}\text { Hoof } \\
\text { coloration }\end{array}$} & Black & 20.8 & \multirow[t]{3}{*}{$12.840^{\mathrm{a}}$} & \multirow[t]{3}{*}{0.002} \\
\hline & White & 58.8 & & \\
\hline & Mixed & 37 & & \\
\hline \multirow{2}{*}{$\begin{array}{l}\text { Hock } \\
\text { injury }\end{array}$} & Normal & 26.9 & \multirow[t]{2}{*}{$7.272^{a}$} & \multirow[t]{2}{*}{0.008} \\
\hline & Injured & 51.7 & & \\
\hline
\end{tabular}


Figure.1 The incidence of different hoof disorders in crossbred dairy cattle in the study area. Keys: IH interdigital hyperplasia, SC scissor claw, HHC horizontal hoof crack, HHE heel horn erosion, WLD white line disease, FR foot rot

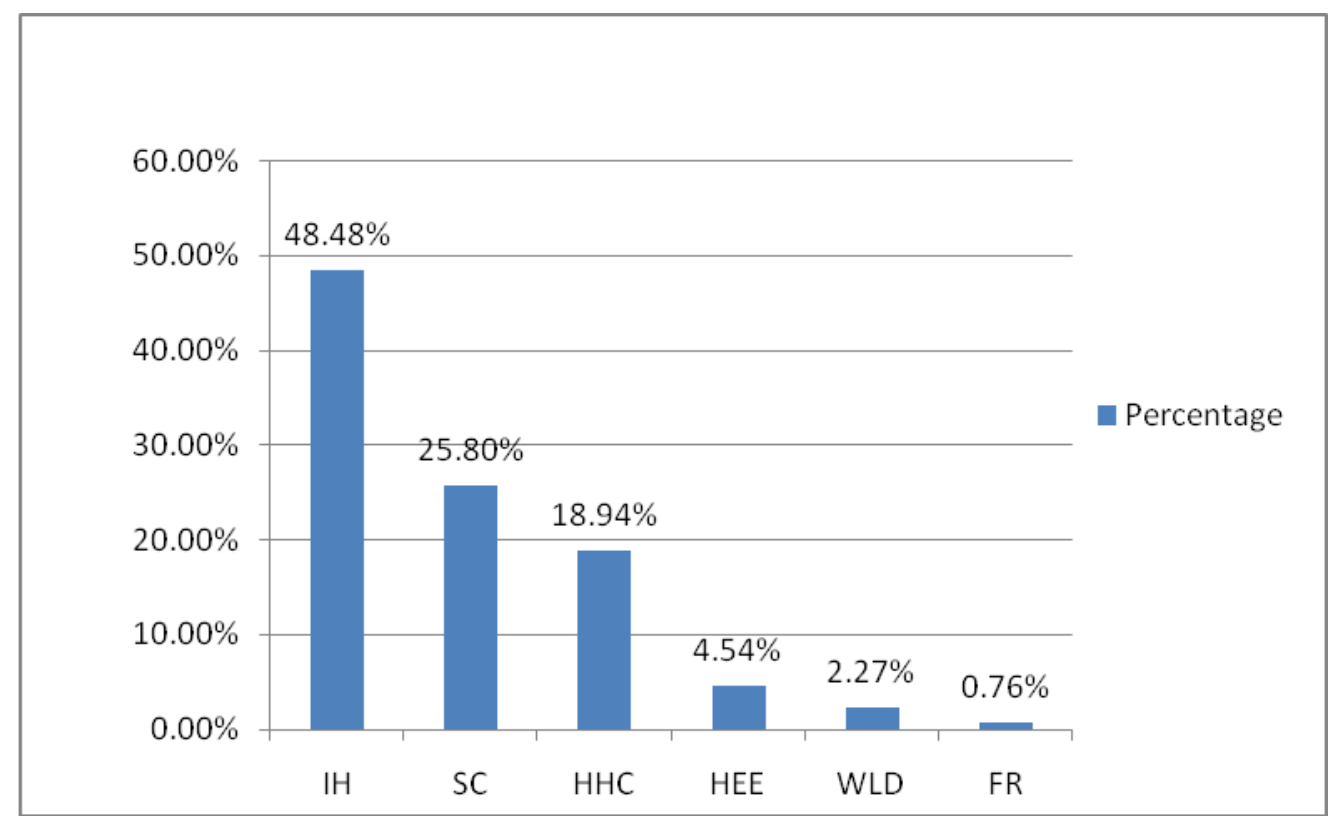

In the present study, the overall incidence of hoof disorders was found to be higher in crossbred cows with white coloured hooves $(58.8 \%)$ followed by mixed $(37.0 \%)$ and black coloured hooves $(20.8 \%)$ (Table 1). Effect of hoof colouration on the incidence of hoof disorders was found significant $(\mathrm{p}<0.01)$ in the present study. It was reported by Chesterton et al., (1989) that less pigmented hooves (more common in Friesian cattle) are more vulnerable to lameness compared to the darker coloured hooves. They also found that Jersey cattle tend to have harder feet and were less prone to lameness. Most of the Jersey crossbred animals have darker coloured hooves and darker coloured hooves are tends to be strong. In present study also $83.58 \%$ Jersey crossbred animals had darker hooves compared to $39.37 \%$ of HF crossbred cows. This can be the reason behind the lower incidence of hoof disorders in Jersey crossbred dairy cattle as they can be sharing the characteristics of stronger hooves from Jersey cows. Similarly, it was also observed by Sogstad et al., (2011) that animal had lighter coloured hooves were more likely to be suffering from certain claw lesions like sole haemorrhages and white line disease compared to darker claws and similarly animal had mixed coloured hooves were more likely to suffer from sole haemorrhages and corkscrew claws compared to darker coloured claws. There were no significant associations of other claw disorders with claw horn colour in this study. This suggests that the composition of the darker claws is much harder than the light coloured claws.

It can be concluded that HF crossbred dairy cattle are more vulnerable to the incidence of hoof disorders in comparison to Jersey crossbred dairy cattle and incidence of hoof disorders increases with the advancement of age, higher body weight, lighter coloured hooves, injured hock conditions and abnormal claw set in crossbred dairy cattle. It was also revealed in the study that the non-infectious hoof disorders were the most occurring 
lesions in the study area in comparison to infectious lesions.

\section{Acknowledgements}

The first author is thankful to the ICARNDRI for providing financial assistance in terms of institutional fellowship and also thankful to the Farmers FIRST Project, ICAR-NIANP, Bengaluru for providing funds and Director, ICAR-NDRI, Karnal, Director, ICAR-NIANP, Bengaluru and Head, SRSICAR-NDRI, Bengaluru for providing the necessary facilities for carrying out the work.

\section{References}

American Angus Association. 2015. Foot score guidelines. http://www.angus.org/performance/foot score/footscoreposter.pdf. (Accessed on August 18, 2017)

Bagate, M.S., Mahla, J.K., Parikh, P.V., Patil, D.B and Dar, M.U.D. 2012. Incidence of Foot Disorders in Dairy animals - A Retrospective Study. Intas Polivet.13 (II): 192-194.

Bhatt, H.D., Kelawala, N.H., Dabas, V.S., Bhatt, R.H., Jhala, S.K., Suthar, D.N. and Dodia, V.D. 2016. Incidence f Hoof Disorders in Bovine of South Gujarat. International Journal of Science, Environment and Technology. 5: $3346-$ 3351.

Bicalho, R.C., Machado, V.S. and Caixeta, L.S. 2009. Lameness in dairy cattle: A debilitating disease or a disease of debilitated cattle? A cross-sectional study of lameness prevalence and thickness of the digital cushion. Journal of Dairy Science. 92, 3175-3184.

Bran, J.A., Darosb, R.R., Keyserlingk, M.A.G.V., LeBlancc, S.J. and Hotzela, M.J. 2018. Cow- and herd-level factors associated with lameness in small-scale grazing dairy herds in Brazil. Preventive
Veterinary Medicine. 151, 79-86.

Brenninkmeyer, C., Dippel, S., Brinkmann, J., March, S., Winckler, C. and Knierima, U. 2012. Hock lesion epidemiology in cubicle housed dairy cows across two breeds, farming systems and countries. Preventive Veterinary Medicine. 209, 236-245.

Chakrabarti, A. and Kumar, P. 2016. Incidences of Foot Diseases of Cattle In Bihar, India. International Journal of Agricultural Science and Research. 6: 267-272.

Chesterton, R.N., Pfeiffer, D.U., Morris, R.S. and Tanner, C.M. 1989. Environmental and behavioural factors affecting the prevalence of foot lameness in New Zealand dairy herds - A case-control study. New Zealand Veterinary Journal. 37,135-142.

Correa-Valencia, N.M., CastaNo-Aguilar, I.R., Shearer, J.K., Arango-Saboga, J.C and Fecteau, G. 2018. Frequency and distribution of foot lesions identified during cattle hoof trimming in the Province of Antioquia, Colombia (2011-2016), Tropical Animal Health and Production. https://doi.org/ 10.1007/s11250-018-1652-1

Dembele, I., Spink, M., Stehulova, I., Panama, J. and Firla, P. 2006. Factors contributing to the incidence and prevalence of lameness on Czech dairy farms. Czech Journal of Animal Science. 51,102-109

Egger-Danner, C., Nielsen, P., Fiedler, A., Müller, K., Fjeldaas, T., Döpfer, D., Daniel, V., Bergsten, C., Cramer, G. Christen, A.-M., Stock, K. F., Thomas, G., Holzhauer, M., Steiner, A., Clarke, J., Capion, N., Charfeddine, N., Pryce, J.E., Oakes, E., Burgstaller, J., Heringstad, B., Odegard, C. and J. Kofler. 2015. ICAR claw health atlas. First edition. http://www.icar.org/ Documents/ICAR_Claw_Health_Atlas. 
pdf. Accessed 2 August 2017.

Gibbons J., Vasseur, E., Rushen, J. and de Passille, A.M. 2012. A training program to ensure high repeatability of injury of dairy cows. Invited paper to Animal Welfare. 21,379-388.

Green, L.E., Huxley, J.N., Banks, C., and Green, M.J. 2014. Temporal associations between low body condition, lameness and milk yield in a UK dairy herd. Preventive Veterinary Medicine. 113, 63-71.

Hansen, L.B., Cole, J.B., Maix, G.D. and Seykora, A.J. 1999. Productive life and reasons for disposal of Holstein cows selected for large versus small body size. J. Dairy Sci. 82: 795-801.

Horseman, S.V., Roe, E.J., Huxley, J.N., Bell, N.J., Mason, C.S. and Whay, H.R. 2014. The use of in-depth interviews to understand the process of treating lame dairy cows from the farmer's perspective. Animal Welfare. 23, 157165.

Huang Y.C., Shanks, R.D and McCoy G.C. 1995. Evaluation of fixed factors affecting hoof health. Livest. Prod. Sci. 44, 115-124.

Johnson, S.W. 1940. Livestock weights and measurements. Minn. Agric. Exp. Sta. Ext. Folder 70.

Kielland, C., L. E. Ruud, A. J. Zanella, and O. Osteras. 2009. Prevalence and risk factors for skin lesions on legs of dairy cattle housed in freestalls in Norway. $\mathrm{J}$. Dairy Sci. 92:5487-5496.

Lohith, J. 2011. Evaluation of incidence of hoof problems in crossbred dairy cattle under field conditions. MVSc Thesis. ICAR-NDRI, Bangalore, India.

Lohith, J., Reddy, A.O., Nagappa, B. and Manjunath, D.R. 2016. The Study of Incidence of Lameness in Relations to Claw Traits in Crossbred Dairy Cattle under Field Conditions. International Journal of Livestock Research, 6, 31-36.
Monsi, A. 1992. Appraisal of interrelationships among measurement at different ages in meat-type chicken. Nigerian. J. Animal Produ. 19:15-24.

Moreira, T.F., Nicolino, R.R., de Andrade, L.S., Filho, E.J.F. and de Carvalho, A.U. 2018. Prevalence of lameness and hoof lesions in all year-round grazing cattle in Brazil. Tropical Animal Health and Production. 50,1829-1834.

Mostafa, A.S and Mahran, H.A. 2016. Assessment of welfare and health of dairy cows under different housing and management systems. Journal of Applied Veterinary Sciences. 1, 57-69

Raber, M., Lischer, C., Geyer, H. and Ossent. P. 2004. The bovine digital cushion-A descriptive anatomical study. Vet. J., 167:258-264.

Rowlands, G.J., Russell, A.M. and Williams, L.A. 1985. Effects of stage of lactation, month, age, origin and heart girth on lameness in dairy cattle. Veterinary Record. 117:576-580.

Sadiq, M.B., Ramanoon, S.Z., Mansor, R., Hussain, S.S.S and Mossadeq, W.M.S. 2017. Prevalence of lameness, claw lesions, and associated risk factors in dairy farms in Selangor, Malaysia. Tropical Animal Health and Production. 49, 1741-1748.

Sogstad, A.M., Fjeldaas, T., and Osteras, O. 2011. Association of claw disorders with claw horn colour in Norwegian red cattle - a cross-sectional study of 2607 cows from 112 herds. Acta Veterinaria Scandinavica. 53, 59.

Solano, L., Barkema, H.W., Mason, S., Pajor, E.A., LeBlanc, S.J., Orsel, K. 2016. Prevalence and distribution of foot lesions in dairy cattle in Alberta, Canada. Journal of Dairy Science. 99, 6828-6841.

Somers, J. and O'Grady, L. 2015. Foot lesions in lame cows on 10 dairy farms in Ireland, Irish Veterinary Journal. 68, 
10

Tadich, N., Flor, E., Green, L., 2010. Associations between hoof lesions and locomotion score in 1098 unsound dairy cows. Veterinary Journal, 184, 60-65.

Thomas, H.J, Remnant, J.G, Bollard, N.J, Burrows, A., Whay, H.R., Bell, N.J, Mason, C. and Huxley, J.N. 2016. Recovery of chronically lame dairy cows following treatment for claw horn lesions: a randomised controlled trial. Veterinary Record. 178, 116.
Whay, H. R., D. C. J. Main, L. E. Green, and A. J. F. Webster. 2003. Animal-based measures for the assessment of welfare state of dairy cattle, pigs and laying hens: Consensus of expert opinion. Anim. Welf. 12:205-217

Whay, H.R., and Shearer, J.K. 2017. The impact of lameness on welfare of the dairy cow. Veterinary Clinics of North American Food Animal Practice. 33, $153-164$.

\section{How to cite this article:}

Rohit Kumar, Mukund A. Kataktalware, S. Senani, M. Sivaram, G. Letha Devi, S. Jeyakumar and Ramesha, K.P. 2019. Risk Factors Associated With the Incidence of Hoof Disorders in Crossbred Dairy Cattle under Field Conditions. Int.J.Curr.Microbiol.App.Sci. 8(03): 22842292. doi: https://doi.org/10.20546/ijcmas.2019.803.272 